\title{
Deconstructing Maternal Semiotic and Paternal Symbolic: A Psycholinguistic Perspective for Social Refinement
}

\author{
Dhara Rathod \\ Department of Business and management, Institute of Advanced Research, Gandhinagar. \\ Email: dhara.rathod87@gmail.com
}

\begin{abstract}
:
To examine the possibilities of reciprocal relationship of Semiotic and Symbolic in language processing, the present study attempts to analyze the psycholinguistic perspective as an essential tool for social refinement. When the select semiotic used for female which is maternal gets its signification in symbolic which is paternal was found affective. Genially, there should no such ideas as masculine or feminine in semiotic and symbolic. Consciously or unconsciously, female locates her priming words as an auxiliary and thereafter the psycholinguistic perspective for social change demands influence of semiotic and symbolic congruency for women empowerment in the globalized era. To transmit, receive and deform meanings of the words that have been used, misused and abused for females, the present study attempts to analyse select words through psycholinguistic filament of language learning. The finding suggests that this deconstructing psychic and linguistic change demands representation of right semiotic and symbolic interpretation of words at Mirror Stage of language processing.
\end{abstract}

Keywords: Psycholinguistic, feminism, semiotic, symbolic, maternal, paternal, signification, social refinement.

\section{Introduction}

Human has claimed: "I am the unified, self-controlled center of the universe the rest of the world, which I define as the Other, has meaning only in relation to me, as man/father, possessor of the phallus" (Jones, p. 362). This claim centrality has been not only given palm by philosophy and religion but also by language too. The term 'Other', in general context, has been used to describe the one who is separate from one's self. Although it is used extensively in existential philosophy to define the relationship between the self and Other, the definition of the term as it is used in the current postcolonial theory, is rooted in Freudian and post Freudian analysis of the formation of the Subjectivity, most notably in the work of the psychoanalyst and cultural theorist Jacques Lacan. His use of the term involves a distinction between the 'Other' and the 'other' which can lead to some confusion, but it is a distinction that can be very useful in post-colonial theory. In Lacan's theory, the other - with the small 'o'- designates the other who resembles the self, which the child discovers when he looks into the mirror and become aware of itself as a separate being (Bill Ashcroft, 2004, p. 169). The Other - with the capital O - has been called the grande-autre by Lacan, the great Other in whose gaze the subject gains identity. The symbolic Other is not a real interlocutor but can be embodied in other subject such as the mother or the father that may represent it. The Symbolic other is a 'transcendent o absolute poll of address summoned each time that subject speaks to another subject (Bill Ashcroft, 2004, p. 170). The Symbolic discourse is

(C) AesthetixMS 2020. This Open Access article is published under a Creative Commons Attribution Non-Commercial 4.0 International License (http://creativecommons.org/licenses/by-nc/4.0/), which permits non-commercial re-use, distribution, and reproduction in any medium, provided the original work is properly cited. For citation use the DOI. For commercial re-use, please contact editor@rupkatha.com. 
another way through which man reduces it to his terms, objectifies the world, and speaks in place of everyone and everything else including women. Here, an assortment of ideas drawn from various poststructuralist, especially from theorists such as Psychoanalyses of Jacques Lacan and Freud, Derrida' deconstruction and feminist approach of Simone de Beauvoir to the psycholinguistic theory of Julia Kristeva has been presented. By doing so, the present research attempts to inquire how poststructuralists' critical approaches came to be applied to psycholinguistic feminism. At a very small strokes, the present paper shows how language' philosophies are the base of Poststructuralism in general, and feminism in particular with special focus on pscholinguistic feminism. The present study represents feminist aspect as a response to the loss of identical meaning in psycholinguistic, its existence in language and in the approach of some theorists who hold various degrees in the field. Besides Lacan, Jung, and Freud, they are Saussure, Derrida, Julia Kristeva, and Simon de Beauvoir.

Simon de Beauvoir in the famous chapter "Woman: Myth and Reality" of The Second Sex, she discussed that they are only men who had made women the "Other" in society by placing a false sensation of "mystery" around and about them. She adds to her argue that men used this as the pretext not to sympathize and understand either females' problems and not to abet them. According to her, this particular attitude imperfect females' success by sustaining the belief that they were a digression from the normal, and always were strangers practicing to emulate it normality. Hence, persistently, Beauvoir exercised an enduring convince upon modern day feminism. She illustrates:

"One is not born, but rather one becomes a woman. No biological, psychological, or economic fate determines the figure that the human female presents in society; it is civilization as a whole that produces this creature, intermediate between male and eunuch, which is described as the feminine" (Beauvior, 2011, p. 330).

The primordial theme in The Second Sex which is about exactly what the role gender played in our society gives palm to the psychological atmosphere created by the male- dominated society for the females. Secondly, why sexism is wrong is put onward as a philosophical argument.

While biology determines our sexes [male or female], culture determines our gender [masculine or feminine]. Emerged from this culture, females cannot be free unless they threw the very notion of females that had been structured by the society- is the beginning point of The Second Sex. Genially, there are no such ideas as 'masculine' or 'feminine', when they born, they should be equal. Even though, unconsciously or consciously, females locate themselves in an auxiliary feminine environment where they could only think what has been imposed on them.

Remarkably, in line with Beauvior, Julia Kristeva explores the region of overlap between linguistic/ literary theory and psychoanalyses. She analyses the way in which texts are able to confirm and stabilize subjectivity or to put it into question; and how the subject is able to transmit, receive, and deform meanings. She explores the contradictory tensions within and between the unified, rational subject and the coherent, meaningful text, revealing the wayward functioning of desire in both. She links subjectivity and textuality through a series of terms, including 'the symbolic', 'the thetic' and 'the semiotic'" (Grosz, 1989, p. 42).

She uses the term 'the semiotic' idiosyncratically. It has resonances with Saussure's revitalization of the term, which is derived from the Greek term semeion, 'sign'. In her usage it designates the contributions of sexual drives to signification. It must be opposed to the symbolic, understood in Lacan's sense as the law-abiding operations of socio-linguistic systems. All signifying practices and all social subjects are the effects of the interrelation of these terms. The semiotic and the 
symbolic are the two energies or movements enabling the subject to signify, to produce and use sign systems, discourses and to engage in social practices, as well as in their potential subversion. The semiotic is one of the most important propositions that Kristeva uses, as discrete from the discipline of semiotics founded by Saussure. One of Kristeva's major contributions to literary theory is her distinction between two heterogeneous elements in signification: the semiotic and the symbolic. Within Kristeva's writings "semiotic" [le sémiotique] becomes a technical term which she distinguishes from "semiotics" [la sémiotique]. Within signifying process, semiotic elements are the drives as they discharge within language. This drive discharge is associated with rhythm and tone. It is a field of emotional, tied to the impulses, which resides in the prosody and fissures of language rather than in the denotative meanings of words (Julia Kristeva, $<$ https://literaturebg.wordpress.com/2011/10/24/julia-kristeva/>). "[The Symbolic] is the language of transparency, power and conformity, and, as such, is aligned with patriarchal functions in culture which signals the father's name and the father's prohibitions in social and psychic formations (Robbins, 2000, p. 128)". When the select semiotic used for female which is maternal gets its signification in symbolic which is paternal was found affective. Genially, there should no such ideas as masculine or feminine in semiotic and symbolic.

The symbolic, on the other hand, is the element of meaning within signification that does signify whereas the semiotic is this subterranean element of meaning within signification that does not signify. The symbolic is associated with syntax or grammar and with the ability to take a position or make a judgment that syntax engenders. The semiotic challenges and gives rise to the symbolic. Kristeva describes the relation between the semiotic and the symbolic as a dialectic oscillation. Without the symbolic we have only delirium or nature, while without the semiotic, language would be completely empty, if not impossible. We would have no reason to speak if it were not for the semiotic drive force. So this oscillation between the semiotic and the symbolic is productive and necessary. It is the oscillation between rejection and stasis, found already within the material body that produces the speaking subject. Kristeva's own writing seems to be governed by this logic of oscillation between symbolic identity and semiotic rejection or difference.

Though most of Kristeva's work deals with psychoanalyses, her Revolution in Poetic Language, as Kelly Oliver observes, describes semanalysis as a combination of semiology [or Semiotics], which starts with Ferdinand de Saussure, and psychoanalysis, which starts with Sigmund Freud (Oliver, 1st January 2015). Now this very oscillation of semiotic and symbolic can function as psycholinguistic. Grosz illustrates it rightly:

"...If [Saussurian] semiotics is the study of signs and sign-systems, semanalysis is the study of sign-deformation and its exorbitant processes and excesses, making signification both possible and questionable. In place of traditional presumptions about the unity of the sign, she poses its radical alterity, its fundamentally split, always open-ended, difference. In place of a structured, rule-bound sign system, she focuses on the becoming, of the processes involved in representation" (Grosz, 1989, p. 6o).

To examine the possibilities of reciprocal relationship of Semiotic and Symbolic in language processing, the present study attempts to analyze the psycholinguistic perspective as an essential tool for social refinement.

By working upon rethinking of sexual identities, Kristeva aims at establishing her own system of thinking to value the significance of feminine. "Insofar as she speaks, insofar as she works, woman is part of the symbolic; yet she is not positioned there in the same way as the male. For one thing, 
where he is positioned in the symbolic with the attributes of active, subject and phallic, she is positioned as object, passive and castrated. The symbolic [that is, masculine] subject is the subject who can say 'I' of himself; it is never clear that in saying 'I' the feminine subject is not in fact referring to a [masculine] 'you'. If women are subjects in the symbolic at all [and not simply objects for other subjects], they are not subjects in the same ways as masculine subjects" (Grosz, 1989, pp. 67-8).

How this semiotic and symbolic [if not] oscillation challenges and subverts subject, and subject being part of language - is an interesting psycholinguistic filament. However, in order to understand how Kristeva's subject-in-process takes shape within her work, her concepts of Semiotics \& Symbolic have been psychoanalytically understood as subject's relation to language. Rejecting the Freudian theses of a universal preexistent subject, the Ego, and of a sexuality located in the realm of instinctual drives, Lacan argues that subject and sexuality are not biologically but linguistically constructed (Lacan, 1968). Both Lacan and Derrida overcome Saussure's conception of language as a stable system based on the inseparable link between signifier and signified; in particular, Derrida points out the dynamism of language due to the endless 'différance' of meanings (Cetorelli). To add, Grosz has cleverly shortlisted in the summary of the second chapter:

"Thus although these movements are correlated with sexual characteristics, they are not readily coded in terms of male/female sexual identities. Rather, within each subject and each social and signifying practice, there is a play of masculine and feminine, a play not of sexual difference but of differentiation" (Grosz, 1989, p. 69).

Most prominently, Kristeva provokes us to investigate the postulation, which is widespread in Western thought, that as an abstract system, language is capable to produce rational and unified subjects and that syntax, in fastidious, provides to stable language to relatively inflexible rules by subjecting expression: so to say, that a normal language secures a normal mind. With the purpose to challenge or confront this assumption, she posits a continuing tension flanked by two different conflicting linguistic modalities: the symbolic and the semiotic;

"The subject is produced as such by the interaction of the semiotic and the symbolic, signifying systems and systems of meaning [linguistic or extra-linguistic], which imply the subordination of the semiotic to the symbolic" (Grosz, 1989, p. 49).

What Kristeva identifies 'the semiotic' puts us back to the childhood' pre-linguistic states where the child gibbers the sounds s/he hears, or where s/he articulates stresses, alliterations or rhythms, trying to reproduce his/her surroundings. In the particular state of mind, the child doesn't hitherto have the necessary linguistic signs and therefore there is no meaning at all in the severe sense of the term. It is just after the mirror phase or the experience of castration in the Oedipus complex that the entity becomes subjectively competent of captivating on the language' mirror phase, of articulation as it has been prearranged - that's what Kristeva calls 'the symbolic'.

As Semiotic and Symbolic posit in meaning making process, family-based socialization practices play a crucial role in the processes of subject construction. To validate the maternal semiotic and paternal symbolic, the present research paper attempts to analyze the text of Amrita Pritam's Pinjar. Here are some textual examples of the same: 'bangles, unclean body, rape, abduction, burden, slut, whore, chastity, purity etc.

If the semiotic process for 'body was unclean' takes place to symbolize a meaning; it only makes meaning in feminine context even without use of pronoun -'her'. It is directly indicated with the reference to the females as females' bodies symbolize purity, chastity and morality. Even words 
like 'slut' and 'whore' are coded in such a way that it only get meanings in females' spoil body, the s. The same expression has not been placed by males in the symbolic as they [masculine] are part of symbolic and feminine are symbolic. Hence, the social signification for the 'unclean body' rest its meaning not by the positing its opposite or different meaning; 'clean and proper body'.

Abduction, rape, murder and lose of purity and chastity became the daily talk of the day at the time of partition, hence, Pritam aptly writes:

"Pooro's parents were resolved to lighten themselves of the burden of a daughter" (Pritam, 2009, p. 3).

'Burden of a daughter' and some words like 'booked', 'matrimonial exchange', 'bangle was the symbol of marital bliss', 'dowry', 'dirty duppata' (Pritam, 2009, pp. 3, 7), are the coded terms for females. Within, as Elizabeth Grosz summarizes kristevan concepts, "each social and signifying practice, there is a play of masculine and feminine" (Grosz, 1989, p. 69). Here, this play of feminine and masculine palms meanings to the words that are used for females; not in the feminist context but in the symbolic of masculine.

About signification of feminine in language, Kristeva asserts that "woman is part of the symbolic; yet she is not positioned there in the same way as the male. For one thing, where he is positioned in the symbolic with the attributes of active, subject and phallic, she is positioned as object, passive and castrated" (Grosz, 1989, pp. 67-8). Being object, passive and castrated, females have been used as an object of the masculine subjects only and ultimately her existence and life survival become dependent on their males. Helplessness, nowhere to go, and uprooted state has been aptly presented by Amrita through the mouth of Pooro: "Where can I go? Whom am I related to except to you?" (Pritam, 2009, p. 26).

Besides, Pooro expresses her grief:

"To sons are given homes and palaces;

Daughters are exiled to foreign lands" (Pritam, 2009, p. 11)

After marriage, daughters are being exiled for others [land and people], previously she was object to manage household in her Father's house and then she is the object for family prestige, chastity, her husband's desire and to birth baby and nurturing. In brief, she has been changing her name, identity and HOUSE to find a perfect HOME for her. If she is married in accordance with her father's desire, she can be called to be abducted by the familiar persons as she is not married to the person of her own choice, but when she is abducted, she is not rehabilitated with the same prestige and position. Rashida pretends to Pooro, "You have no place in that home now" (Pritam, 2009, p. 26).

It has been hierarchy of the male dominated society to void females' to value male. Till present day in the society, females get a distinguished state of respect if she has given birth to a baby boy. At the time of Javed's birth, midwife allegorically elaborates:

\section{"Sons do not drop down through the ceiling, do they?" (Pritam, 2009, p. 32).}

Here, "the words as signifier do not signify the signified" (Barad, 2010), but what they signify is the preference that society gives to boy-child. Does it have denotative meaning or signification like daughters drop through the ceiling? The question tag, used here, indicates a kind of positive assertion that the midwife wanted to get from Rashida. Moreover she rejoice her feelings by saying, 
“Congratulations, son. You have been blessed with a son" (Pritam, 2009, p. 32 ).

If females have the same position in symbolic as masculine subjects are, society might not have avoided birth and birthright of females. The anxiety of having a girl child is echoed in the novel when Pooro's mother began to sing a daughter' lament:

"O mother of mine, clasp me to your bosom

And answer just one question

Tell me not a long tell.

Tell me why you bore me

If tonight we have to depart?" (Pritam, 2009, p. 11).

"The symbolic [that is, masculine] subject is the subject who can say 'I' of himself; it is never clear that in saying ' $\mathrm{I}$ ' the feminine subject is not in fact referring to a [masculine] 'you'. (Grosz, 1989, pp. 67-8). 'I' and 'feminine subject', while conquering the concept of identity Kristeva asserts, is not that the subject is equal to nothingness, but instead that the subject is just about (non)existent. It is due to the acceptance of the identity that almost exists as non-existent, Pooro remains stranger to her own identity.

By illustrating how an imbricative process of just changing the names of the fictional characters, writer of our selection has presented the loss of identity which is also an illustrious topic by our theorist, Kristeva. As she does not possess her own identity, she ultimately remains strangers to herself:

"I have become a stranger in my own home. The home which gave me birth has now become my coffin..." (Pritam, 2009, p. 103).

Here, consciously or unconsciously, female locates her priming words as an auxiliary and thereafter the psycholinguistic perspective for social change demands influence of semiotic and symbolic congruency for women empowerment in the globalized era. After transmitting, receiving and deforming meanings of the words that have been used, misused and abused for females, select words from select fiction have been analysed through psycholinguistic filament of language learning. The finding suggests that this deconstructing psychic and linguistic change demands representation of right semiotic and symbolic interpretation of words at Mirror Stage of language processing. The mirror stage provides the barest differentiation between the signifier and signified, positing them as two orders within signifying practices.

\section{Works Cited}

Barad, D. (2010). Kamala Das: Stranger to Herself. In S. C. Mouli (Ed.), Charisma of Kamala Das. New Delhi: Gnosis.

Beauvior, S. d. (2011). The Second Sex. New York: Vintage Bools Edition.

Bill Ashcroft, G. G. (2004). Key Concepts in Post Colonial Studies. London and New York: Routledge.

Cetorelli, V. (n.d.). Re-Thinking Subjectivity in French Psycholinguistic. Essex Graduate Journal of Sociology, Volume 10. 
$7 \mid<$ Works Cited

Grosz, E. (1989). Sexual Subversions: Three French Feminist. NSW, Australia: Allen \& Unwin.

Jones, A. R. (n.d.). Writing the Body: Towards the Understanding of Ecriture Feminine. In E. Showalter, The New Feminist Criticism: Essay on Women, Literature an theory (pp. 361-377). New York: Pantheon Books.

Julia Kristeva. (<https://literaturebg.wordpress.com/2011/10/24/julia-kristeva/>). 24 october 2011: 11 July 2014.

Lacan, J. (1968). The Language of the Self. Baltimore: John Hopkins Press.

Oliver, K. (1st January 2015). Kristeva, Julia. In M. G. Kreiswrth, The John Hopkins Guide to Literary Theory and Criticism (p.

<http://www.press.jhu.edu/books/hopkins_guide_to_literary_theory/julia_kristeva.html>). 23rd June 2004: The John Hopkins University Press.

Pritam, A. (2009). Pinjar. Trans. Khuswant Singh, The Skeleton and other Stories New Delhi: Tara Press. Robbins, R. (2000). Literary Feminisms. Palgrave Macmillan. 